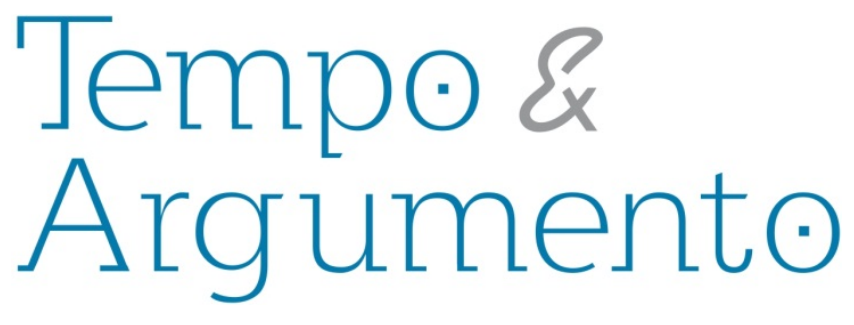

\title{
Monumento Estela de Luz: disputas en torno a los usos públicos de la historia en el México del Bi/Centenario
}

\begin{abstract}
Resumen
Este artículo parte de la premisa de que actualmente es imprescindible para los historiadores reconocer la importancia de la vida pública y de los usos públicos de la historia, e involucrarse activamente en los debates sobre la representación del pasado en contextos que exceden la práctica disciplinar y los espacios académicos. Para ello, se propone un caso de estudio concreto: la Estela de Luz, monumento erigido en México, en el 2010, ocasión del Bicentenario de la Independencia y Centenario de la Revolución. Un examen de la historicidad de la Estela -de su planeamiento y ejecución; de sus críticas y resignificaciones-, permite dar cuenta de las maneras en que diversos actores sociales contienden en la arena pública por el sentido de la historia.
\end{abstract}

Palabras clave: Monumento, Usos públicos de la historia, México, Bi/Centenario, Estela de Luz.

\section{Para citar este artículo:}

VARGAS ÁLVAREZ, Sebastián. Monumento Estela de Luz: disputas en torno a los usos públicos de la historia en el México del Bi/Centenario. Tempo e Argumento, Florianópolis, v. 8, n. 19, p. 130 - 161, set./dez. 2016.

\author{
DOI: $10.5965 / 2175180308192016130$
}

http://dx.doi.org/10.5965/2175180308192016130 


\title{
Estela de Luz monument: struggles on public uses of history in Bicentennial Mexico
}

\begin{abstract}
This paper argues that nowadays is essential for historians recognize the importance of public life and public uses of history, and engage actively in discussions on the representation of the past in contexts that exceeds the disciplinar and academic practice. For this purpose, a specific case study is proposed: Estela de Luz, a monument built on the ocassion of Mexico's Bicentennial of Independence and Centennial of Revolution commemoration (2010). An examination of the historicity of the Estela -the planning and execution of the monument; but also its criticism and resignifications-, can help us to understand how a diversity of social actors contends for the sense of history in the public arena.
\end{abstract}

Keywords: Monument, Public uses of the past, Mexico, Bicentennial, Estela de Luz.

\section{Introducción}

Hace ya casi treinta años que Jürgen Habermas y Jeremy Leaman publicaron el determinante ensayo "Concerning the public use of history" (1988), una respuesta al historiador conservador Ernst Nolte que hace parte de la discusión pública sostenida en Alemania entre 1986 y 1989 conocida como Historikerstreit (el debate de los historiadores). Éste versó sobre la responsabilidad histórica de los alemanes, la singularidad histórica (o no) del Holocausto (y por ende, el negacionismo o reconocimiento del mismo) y la pérdida de identidad nacional. En el texto, los autores se referían a la imposibilidad de desconocer el acontecimiento traumático, de pasar la hoja sobre un "pasado que no pasa", y la imperiosa necesidad de hacerse cargo de dicho 
Años después, en reflexión similar, pero situada en el contexto de la India poscolonial, Dipesh Chakrabarty proponía el concepto de "vida pública de la historia" para designar las conexiones que la historia como disciplina científica puede (y debe) forjar con instituciones y prácticas sociales por fuera de la universidad y de la burocracia oficial, para asumir un rol pertinente en los debates sobre el pasado en el mundo de hoy. Pensando en cómo sacar a la práctica historiográfica de su enclaustramiento académico, Chakrabarty se preguntaba “¿bajo qué condiciones pueden la historia y los historiadores desempeñar un papel de juicio cuando las disputas relacionadas con el pasado surgen en el ámbito de la cultura popular en las democracias?" (2008, p. 169).

Hago referencia a los conceptos de "usos públicos de la historia" o "vida pública de la historia" porque nos permiten pensar cómo en la actualidad el pasado se ha convertido en un dominio disputado, dirimido y significado por diversos actores sociales en la esfera pública, excediendo el ámbito historiográfico. Dichos conceptos nos invitan a reflexionar "sobre las diversas estrategias e intereses del uso público del conocimiento histórico, las diferentes formas de gestión del pasado histórico y de la memoria colectiva", lo cual "parece cada vez más consciente y más necesario, tanto para los propios historiadores como para el conjunto de la sociedad" (CARRERAS y FORCADELL, 2003, p. 13).

Los usos públicos de la historia, su vida pública, pueden rastrearse en diversos registros, soportes o formatos que dan cuenta de los conflictos, tensiones y luchas entre diferentes relatos del pasado por posicionarse como "verdaderos" o "hegemónicos". En este sentido, los museos, las conmemoraciones o los monumentos se constituyen en archivos a los ojos de historiadores interesados por las políticas de la memoria y el olvido que se tejen a su alrededor. Este artículo aborda el caso de la Estela de Luz, monumento erigido en México, en el 2010, ocasión del Bicentenario de la Independencia y Centenario de la Revolución. Un examen de la historicidad de la Estela -de su planeamiento y

\footnotetext{
${ }^{1}$ Los principales ensayos que hicieron parte del contrapunto entre Habermas y Nolte aparecen traducidos al castellano en Habermas, Mann y Nolte (2012). Sobre el debate de los historiadores, ver La Capra (2008).
} 
ejecución; de sus críticas y resignificaciones-, evidencia la manera en la que en el México contemporáneo la historia permanece abierta así quiera cerrarse y petrificarse: es un campo de batalla. Lo interesante es que dicha batalla se lleva a cabo en el ámbito de lo público, en la calle y la plaza, sobre el monumento mismo, lo cual refuerza la utilidad de los conceptos antes mencionados. Es fundamental que los historiadores prestemos a estos espacios y debates la atención que merecen, y participemos activamente de su desarrollo.

Este texto está dividido en tres secciones. En primer lugar, defino teóricamente lo que entiendo por monumento. Luego, paso a abordar el caso de la Estela de Luz en el contexto de la conmemoración del Bicentenario mexicano, describiendo su planeamiento original y las vicisitudes de su construcción. Posteriormente, me enfoco en los cuestionamientos, apropiaciones y desplazamientos de la Estela, en diferentes momentos y por parte de distintos actores colectivos. Finalmente, se presentan unas breves conclusiones sobre los usos públicos de la historia a partir del caso de estudio elegido.

\section{Monumento: memorias inscritas en el espacio público}

El término "monumento", proviene del latín (monere: advertir; mentum: medio, instrumento, modo), y designa una "obra pública y patente, en memoria de alguien o de algo", una “construcción que posee valor artístico, arqueológico, histórico”. En muchas ocasiones el monumento cumple la función funeraria, real o simbólica, de "sepulcro (obra para dar sepultura a un cadáver)" (RAE, 2014).

Desde épocas remotas, y en múltiples sociedades, se han erigido monumentos en honor a los ancestros de la comunidad, como una manera de rememorar el pasado para legitimar y dar sentido al presente.

Memoria, comunidad y relato o preservación del pasado han estado ligados desde siempre en la construcción de monumentos, especialmente en los funerarios. Más aún, muerte y monumento, memoria y comunidad, pasado y relato del pasado han sido materia permanente de las más diversas sociedades a lo largo de la historia (ACHUGAR, 2003, p. 198). 
La doble condición del monumento (lugar de rememoración y sepulcro) radica en la relación que la obra/construcción instaura entre los vivos y los muertos: relación de deuda y de identificación de los vivos (quienes levantan el monumento y tienen la responsabilidad de recordar, imitar y repetir el ejemplo de los ancestros) con los “difuntos gloriosos” (SMITH, 1998, p. 67). La función política del monumento es, por ende, hacer coincidir el sentido de la muerte de los antepasados -o contemporáneos sacrificados en nombre de la comunidad- con la fundación de sentido de los supervivientes para invocar "una identidad común de los vivos y los muertos" (KOSELLECK, 2011, pp. 68-69); o dicho de otra forma, engendrar una conexión/continuidad entre el pasado y el presente de la comunidad, que le permita convertirse en una "comunidad de historia y de destino" (SMITH, 1998, p. 70). Esta función resulta todavía más evidente después de la Revolución Francesa y con la emergencia de los Estados nacionales modernos: retomando la figura cristiana del mártir, los monumentos comienzan a codificarse a partir de los nacionalismos -nuevas religiones civiles- para venerar a los héroes, "padres de la patria" o soldados anónimos, cuya presencia fantasmática influye en nuestras acciones presentes (y futuras) ${ }^{2}$.

La identidad o conexión/continuidad entre vivos y muertos invocada en el monumento cobra sentido si tenemos en cuenta que la dimensión espacial es uno de los apoyos o condiciones principales de la memoria colectiva. Ya lo decía Halbwachs: "no hay memoria colectiva que no se desarrolle dentro de un marco espacial" (2004, p. 144) 3 $^{\text {. Para }}$ comprender los procesos de construcción (y contestación) de las identidades modernas, entonces, es necesario prestar atención a la manera como se elabora y transmite la memoria social en el espacio (no como algo objetivo y dado, sino también como una construcción social) ${ }^{4}$. En otras palabras, "la fabricación del lugar, como techné de la memoria pública (o más acertadamente, como coordinación de varios technés), se

\footnotetext{
${ }^{2}$ Según Koselleck, la configuración de las memorias nacionales en la modernidad "democratiza" el culto a la muerte, antes restringido a reyes y nobles. El mejor ejemplo de este desplazamiento es el monumento a los soldados desconocidos, que se popularizó en Europa después de la Primera Guerra Mundial (2011, pp. 94-98). Para el caso colombiano, ver Bernardo Tovar (1998).

3 El sociólogo francés dedicó todo un capítulo al tema: "La memoria colectiva y el espacio" (2004, pp. 131161).

${ }^{4}$ Juntos, memoria social y espacio social se articulan para producir el contexto de las identidades modernas -y las frecuentemente rigurosas contestaciones de dichas identidades. (HOELSCHER y ALDERMAN, 2004, p. 348).
} 
convierte en algo vital para cualquier comprensión de los medios por los cuales la memoria es formada y puede ser apropiada" (DICKINSON, BLAIR y OTT, 2010, p. 25). EI vínculo entre memoria y espacio, ya sea que se establezca a través de artefactos materiales (como los monumentos), o de "geografías imaginadas", debe contribuir al sentimiento de continuidad de la comunidad no solo en el tiempo, sino también en el territorio.

Ahora bien, los monumentos, a diferencia de otras huellas o vestigios del mundo pasado, son voluntarios: fueron creados para perdurar. Son producto de políticas de memoria específicas que fijan una representación del pasado y la establecen como la

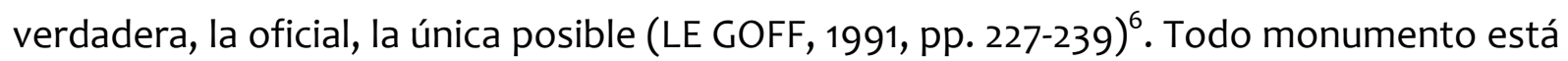
precedido por una serie de decisiones sobre el recuerdo y el olvido que remiten a las relaciones asimétricas e inestables de poder que atraviesan a la sociedad donde éste está presente:

El monumento, en tanto hecho monumentalizado, constituye la celebración del poder, del poder tener el poder de monumentalizar [...] Pero, al mismo tiempo, la representación es un borramiento, una tachadura, una cancelación pues el monumento borra, tacha, cancela toda otra posible representación que no sea la representada por el monumento [...] de ese modo realiza el mayor efecto del poder de la representación y la celebración: condena al olvido, a la invisibilidad, a la no presencia de aquello o aquellos que no tienen el poder para representarse o ser representados (ACHUGAR, 2003, p. 206).

Esta característica de inclusión/exclusión es compartida por otros soportes de la memoria o formas discursivas de representación del pasado, como la historiografía, o las conmemoraciones rituales. Lo que distingue al monumento es la "petrificación": la capacidad, gracias a su materialidad y quietud, de generar una ilusión de inmutabilidad y

\footnotetext{
${ }^{5}$ El concepto "imaginative geographies" es propuesto por Edward Said para referirse a la manera en que interactúan memoria y geografía en diferentes relatos (literatura, pintura, historiografía) en procesos de conquista y dominación propios de contextos (pos)coloniales (2011). En su ensayo, Said explica cómo a lo largo del siglo XX el sionismo israelita imaginó a Palestina como un "lugar" desde siempre desierto (de seres humanos, de cultura, de historia); esta imaginación geográfica justifica y mantiene las relaciones de poder y ocupación actuales de Israel sobre Palestina.

"Es debido al carácter "voluntario" del monumento que debemos acercarnos a ellos de una manera crítica, teniendo en cuenta que no son un reflejo fiel del pasado al que refieren, sino una visión del pasado que sus creadores querían legar a la posteridad; no es su mundo, sino como ellos querían que las futuras generaciones vieran su mundo.
} 
permanencia en el tiempo y espacio que contribuye a consolidar y naturalizar las representaciones que despliega como "verdad": se convierten en "afloramientos geológicos en un paisaje nacional", tan naturales e idealizados como el paisaje donde están inmersos (YOUNG, 2011, p. 381). La paradoja del monumento como uno de los lugares de memoria más poderosos de una comunidad, es que esa misma cualidad de petrificación, en vez de dar vida y dinamismo a la memoria, la bloquea y obtura:

Está meridianamente claro que todo monumento erigido lleva consigo el peligro de la petrificación. Da igual que se convierta en bronce o piedra: siempre que el recuerdo se materializa en un monumento cabe no menospreciar el peligro de que, precisamente porque fija institucionalmente formas de recuerdo, bloquee el propio recuerdo (KOSELLECK, 2011, p. 48).

Al imponer una versión única de la historia, los monumentos podrían obturar en lugar de propiciar el acceso al pasado, y al formularse esa narración en forma rotunda y definitiva, coartar la posibilidad de promover un diálogo, interrogar activamente o formular nuevas interpretaciones futuras sobre lo ocurrido (SCHINDEL, 2009, p. 77).

Los monumentos encarnan y legitiman un régimen político, un orden social, una historia. Es por eso que cuando estos regímenes, órdenes e historias son desafiados por revoluciones u otras movilizaciones, los monumentos son uno de los primeros blancos de ataque. Casi siempre son destruidos, como la estatua de Antonio López de Santa Anna en la Plaza del Volador (Ciudad de México), derribada en 1844 por la creciente impopularidad del presidente; o la columna con la efigie de Napoleón de Place Vendôme, que corrió la misma suerte durante el levantamiento de la Comuna de París en 1871 (ZÁRATE, 2003, pp. 420-421). Al final de la película Adiós a Lenin (2003) vemos cómo un helicóptero retira una estatua del líder comunista de una de las plazas de Berlín Oriental: la escena simboliza dramáticamente el final del régimen político, a la vez que evidencia la pretensión de borrar su memoria pública?.

Otra estrategia para deshacerse de los monumentos "indeseables", que remiten a un pasado que ya no se adecua a la nueva formación social o que simplemente no concuerda con los valores o intereses de las elites de turno, es el desplazamiento:

\footnotetext{
${ }^{7}$ Adiós a Lenin, dirigida por Wolfgang Becker (2003). Esta película se sitúa en el contexto de la caída del muro de Berlín y la desaparición de la República Democrática Alemana en 1989.
} 
México hasta finalmente llegar a la entrada del barrio Tepito, o las estatuas de los tlatoanis aztecas Ahuizotl e Izcóatl, los "Indios Verdes", inicialmente colocadas a la entrada del Paseo de la Reforma, luego en el Canal de la Viga, y desde 1920 en el extremo norte de la avenida de Los Insurgentes, donde actualmente "están prácticamente ocultas en un mar de pasos a desnivel para vehículos y transeúntes que utilizan la estación del metro Indios Verdes" (ZÁRATE, 2003, p. 422).

Ya sea que sean derrumbados o trasladados a la periferia, o bien, restaurados, bien mantenidos y venerados, los monumentos no retienen indefinidamente el sentido, la representación, la idea original con la que sus creadores los dotaron: cabe la posibilidad de que sean reinterpretados, reapropiados y resignificados. Como nos recuerda Pierre Nora, si bien la función de los lugares de memoria es “detener el tiempo, bloquear el trabajo del olvido, fijar un estado de cosas, inmortalizar la muerte, materializar lo inmaterial", lo interesante es que éstos no pueden existir sino "por su aptitud para la metamorfosis, el incesante resurgimiento de sus significaciones y la arborescencia imprevisible de sus ramificaciones" (2008, p. 33). En una perspectiva similar, y reflexionando sobre las luchas por la memoria de los desaparecidos en la historia reciente de América Latina, Elizabeth Jelin y Victoria Langland plantean:

Aunque se quiera cristalizar en la piedra o en la ruina preservada, aunque la materialidad de la marca se mantenga en el tiempo, no hay ninguna garantía de que el sentido del lugar se mantenga inalterado en el tiempo y para diferentes actores. Siempre queda abierto, sujeto a nuevas interpretaciones y resignificaciones, a otras apropiaciones, a olvidos y silencios, a una incorporación rutinaria o aun indiferente en el espacio cotidiano, a un futuro abierto para nuevas enunciaciones y nuevos sentidos (2003, p. 15).

Esta apertura a futuras nuevas enunciaciones y sentidos, nos advierten las autoras, no es azarosa, sino que obedece a discursos hegemónicos, luchas ideológicas y proyectos políticos de diversos actores sociales situados en múltiples "presentes" desde donde se interactúa con el monumento. Tener esto en cuenta equivale a reconocer la historicidad 
del monumento, es decir, la cadena de intervenciones, despliegues, usos, circulaciones y rearticulaciones en el tiempo "entre el establecimiento de un lugar y nuestras prácticas actuales en y del lugar" (DICKINSON, BLAIR y OTT, 2010, pp. 30-31). O, en palabras de James Young, reconocer la "vida social del monumento": no solo sus contornos estéticos o su lugar en el discurso estético contemporáneo, sino ante todo la reacción de los espectadores/observadores frente al monumento, particularmente si hacen parte de las nuevas generaciones, quienes "visitan los monumentos en otras circunstancias y las invisten con nuevos significados" (2011, pp. 379-382).

Durante la segunda mitad del siglo XX, la misma función política del monumento ha venido siendo cuestionada, en parte por el surgimiento de una tendencia posmoderna en el arte, la arquitectura y el urbanismo; en parte por la irrupción del acontecimiento límite/traumático (genocidio, desaparición forzada, segregación, etc.) y la inadecuación del monumento tradicional para representarlo/rememorarlo. "Cuando el tema es la ruptura, la ausencia y la pérdida, los $\operatorname{arcos}$ y columnas clásicas que fueron las convenciones duraderas de los monumentos victoriosos ya son insoportables" (TORRE, 2006, p. 20). El movimiento antimonumento (propuesto por artistas alemanes como Jochen Gerz o Norbert Radermacher), que parte de la desconfianza hacia la impronta autoritaria del monumento y propone diversas intervenciones performativas y trabajos de memoria en el espacio público; o la negativa de las Madres de la Plaza de Mayo a erigir un monumento a los detenidos-desaparecidos (que según ellas fijaría formas institucionalizadas de la memoria), y en su lugar su propuesta de una universidad nómada y de un centro cultural, son buenos ejemplos de esta mutación del monumento en la época contemporánea ${ }^{8}$.

Finalmente, es preciso recordar el nexo entre los monumentos y los días de fiesta oficiales. En tanto artefacto conmemorativo, el monumento está estrechamente relacionado con las efemérides. La ceremonia de colocación de la primera piedra o inauguración de un monumento suele ocurrir en una fecha festiva. Una de las principales actividades que tienen lugar en un día conmemorativo, es la inauguración de obras

\footnotetext{
${ }^{8}$ El movimiento artístico antimonumento es analizado por Young a profundidad en The texture of memory (1993). Sobre el caso argentino, ver Estela Schindel (2009). Para otros casos latinoamericanos, ver la compilación de Elizabeth Jelin y Victoria Langland (2003).
} 
públicas y monumentos. Otros actos conmemorativos como discursos, bailes y desfiles, tienen lugar cerca de monumentos y marcas territoriales, erigidos con anterioridad. En 1910, la inauguración de la Columna de la Independencia en México y de la estatua ecuestre a Simón Bolívar en Colombia fueron actos centrales de la conmemoración del Centenario de la Independencia en ambos países. La mayoría de las esculturas conmemorativas y monumentos que se colocaron desde el siglo XIX en el Paseo de la Reforma, aquella avenida pensada como conexión entre el Castillo de Chapultepec y el Palacio Nacional (residencia y sede del gobernante, respectivamente), pero también como un "compendio de la historia nacional", fueron inauguradas el 16 de septiembre, día de fiesta nacional mexicana (MARTíNEZ ASSAD, 2011). Incluso obras de reconstrucción o restauración urbanística más ambiciosas y complejas, como la “invención” del barrio gótico en Barcelona, estuvieron ancladas en fiestas conmemorativas: el proyecto se lanzó en 1903 en el marco del aniversario 700 del rey Jaime I (el monarca aragonés que concedió a la ciudad el gobierno autónomo), y las obras comenzaron en forma en 1929 con motivo de la Exposición Internacional de Barcelona (VENTEO, 2002). Finalmente, las festividades conmemorativas también son fechas propicias para las resignificaciones, cuestionamientos y reapropiaciones alternativas de los monumentos. En el extremo de este espectro de posibilidades de intervención, encontramos el vandalismo, tal como ocurrió con el monumento a Colón ubicado en el Paseo de la Reforma, que sufrió daños al ser atacado por manifestantes durante la conmemoración el 12 de octubre de 1992 del V Centenario del “descubrimiento” de América.

\section{Estela de Luz: monumento del Bi/Centenario mexicano}

En 2010, México, al igual que otros países latinoamericanos (como Colombia, Argentina o Chile), se dispuso a conmemorar los doscientos años de la proclamación de Independencia de la corona española. Así mismo, en dicho año se cumplieron los primeros cien años del inicio de la Revolución Mexicana, por lo que, a diferencia de los otros países, en este caso se trató de una conmemoración doble: un Bi/Centenario. 
A grandes rasgos, puede decirse que la conmemoración oficial a cargo del Gobierno Federal consistió en una abultada agenda conmemorativa, que incluyó ceremonias, desfiles, conciertos y festejos, exposiciones museográficas, programas educativos y de divulgación histórica, entre muchas otras actividades, concentradas en el mes patrio de septiembre (CALDERÓN, 2010). Desde que en el 2006 el entonces presidente Vicente Fox decretara el 2010 como año oficial de los festejos, éstos se concibieron de una manera descentralizada, de tal suerte que cada estado fuera autónomo en sus propuestas conmemorativas, y de que se tuviera en cuenta el carácter “pluricultural” de la nación. Sin embargo, este esquema generó cierta desorganización e inestabilidad en la planeación de los festejos, y en pocos años la comisión organizadora encargada de coordinar la conmemoración cambió en cinco ocasiones de director, pasando de depender del Consejo Nacional para las Artes y la Cultura (CONACULTA), al Instituto de Estudios Históricos de las Revoluciones de México (INEHRM) y finalmente a la Secretaría de Educación Pública (SEP). Las lecturas de la historia y su despliegue en el espacio público estuvieron atravesadas también por tensiones partidistas: el Gobierno Federal, adscrito al Partido de Acción Nacional (PAN), hizo énfasis en el recuerdo de la insurgencia de 1810 dejando la Revolución de 1910 en un segundo plano, y se enfrentó a una agenda conmemorativa alternativa del Gobierno del Distrito Federal, de izquierda y afiliado al Partido de la Revolución Democrática (PRD) (ALLIER y HESLES, 2010; CARRILLO, 2010; GUEDEA, 2012).

Si bien el $\mathrm{Bi} /$ Centenario se planteó como incluyente y multicultural, la retórica de los héroes, batallas y acontecimientos consagrados por la historia patria fue una vez más la que adquirió mayor visibilidad, dejando por fuera o restándole importancia a las dimensiones del pasado y los sujetos históricos tradicionalmente ignorados. En suma, se trató de una conmemoración altamente cuestionada por movimientos sociales, académicos y ciudadanos en general por una falta de sentido o coherencia en el mensaje histórico que se pretendía transmitir en un presente fuertemente atravesado por la crisis económica y la violencia de la guerra contra el narco declarada por el presidente Felipe Calderón (GARCIADIEGO, 2012). También, como veremos más adelante, por la sospecha de despilfarro y corrupción, la falta de claridad en la forma en que se gastaron los recursos para proyectos y festejos. En muchas ocasiones, los mencionados actores 
sociales hicieron públicas sus críticas, así como sus reinterpretaciones del pasado y del presente, en acciones contra-conmemorativas de diversa índole (RíOS, 2015).

Una de las principales actividades conmemorativas fue la construcción de la Estela de Luz: una torre o columna de 104 metros de altura compuesta por dos delgadas placas paralelas que contienen 1.700 piezas de cuarzo, dotada de un sistema de iluminación de alta tecnología (CALDERÓN, 2010, p. 165). Justamente una de sus principales características es la iluminación, pues la estructura se enciende todas las noches emanando una luz de tono blanco, efecto logrado gracias a los módulos de cuarzo. La Estela está ubicada a un costado del Paseo de la Reforma, en la plaza delimitada por la Secretaría de Salud, la Puerta de los Leones (entrada al Bosque de Chapultepec) y el parque Ariel. Se encuentra de esta manera articulada a los demás monumentos, esculturas conmemorativas y sitios históricos-patrimoniales alineados a lo largo de esta avenida (monumento a Colón, a Cuauhtémoc, Columna a la Independencia, Flechadora del Norte, Museo Nacional de Historia-Castillo de Chapultepec). Con la construcción de la Estela de Luz, de hecho, quedó manifiesta la intención del gobierno de Felipe Calderón de inscribirse en la historia nacional al rendir homenaje a la patria a partir de políticas conmemorativas específicas, de la misma forma en que lo había hecho Porfirio Díaz un siglo atrás. En la ceremonia de lanzamiento del concurso arquitectónico para el Bicentenario, el presidente auguró que

por su importancia simbólica y belleza arquitectónica, este monumento se sumará a la majestuosidad de obras tan emblemáticas y admiradas por todos los mexicanos, como son el Ángel de la Independencia, el Hemiciclo a Juárez o el Monumento a la Revolución. Esta obra será un símbolo de orgullo y de unidad para los mexicanos de hoy y para los mexicanos del futuro; será el emblema de una Nación moderna que manifiesta la fidelidad que siente hacia su pasado y que al mismo tiempo busca heredar a las próximas generaciones lo mejor de su cultura, de su arte, de su sensibilidad estética (CALDERÓN, 2009).

El lugar donde se encuentra La Estela se enmarca dentro de uno de los conglomerados financieros más importantes de la ciudad, rodeado por los tres edificios más altos de México (la Torre Mayor, la Torre BBVA y la Torre Reforma). A pesar de esto, “prevalece su verticalidad ya que aunque es más pequeña que estos edificios, también es más esbelta, y con la perspectiva desde la parte inferior, parece como si acabara en 
punta, por lo que muestra un parecido formal y simbólico con la espada, la flecha y el rayo, especialmente por su iluminación que recuerda el fuego encendido" (AJA, 2016, pp. 34-35) ${ }^{9}$. La Figura 1 muestra la representación de este monumento:

Figura 1: Estela de Luz.

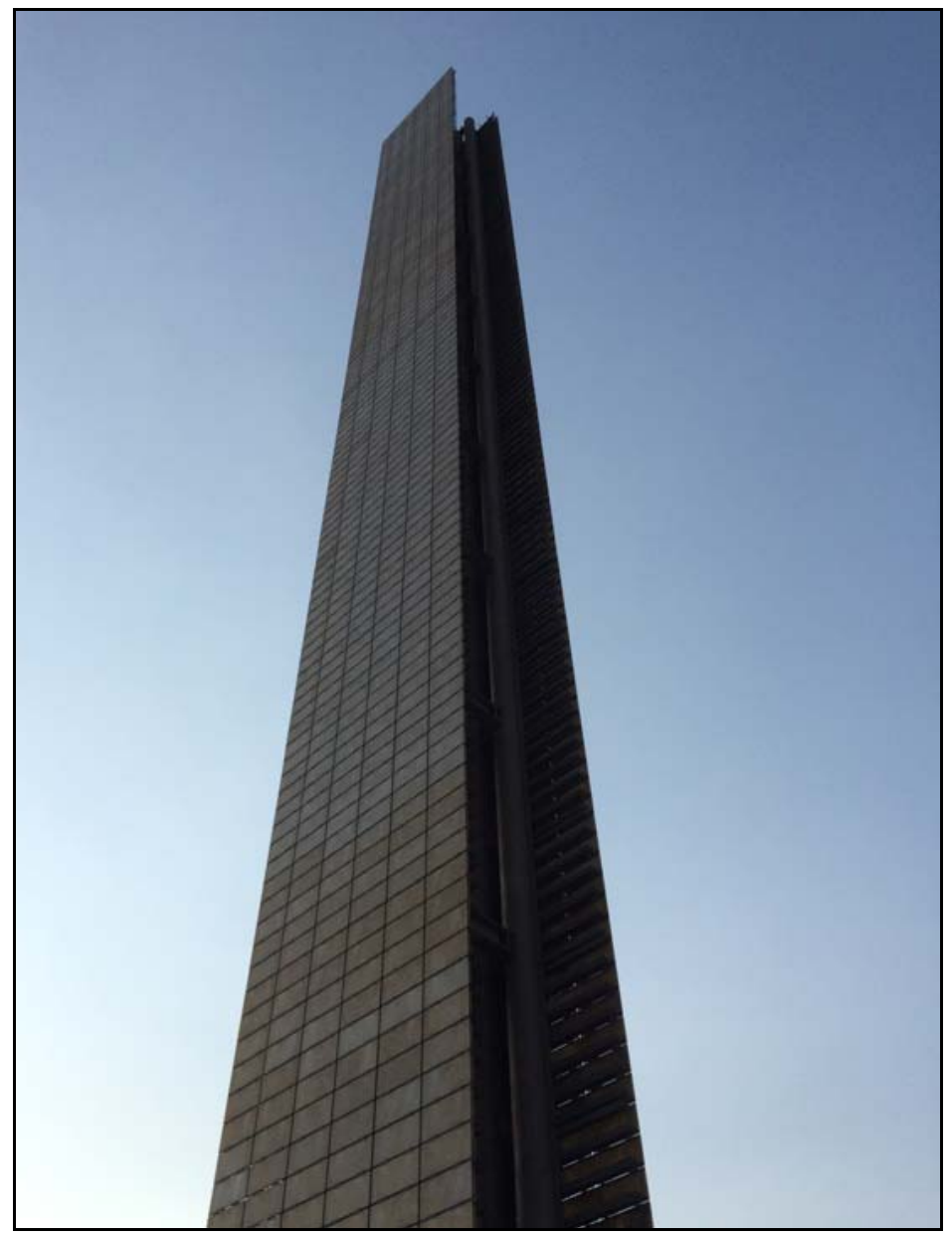

Fuente: Fotografía de Sebastián Vargas (2016).

Según Aja (2016), los monumentos que tienden a la verticalidad, como obeliscos, columnas, o aquellos que son soporte de un fuego encendido, están relacionados con deidades uranianas o celestes. La altura funciona como metáfora de la ascensión, a la vez

\footnotetext{
${ }^{9}$ Incluído en el libro Pasados presentes: debates por las memorias en el arte público en América Latina (2015), el artículo de María del Pilar Aja se ocupa de la Estela de Luz a partir de sus características estéticas y de la pregunta por el lugar del arte en la configuración de la memoria y el imaginario capitalino. En este texto, me interesa aproximarme a La Estela desde la disciplina histórica, pues considero que es un ejemplo que posibilita la reflexión sobre nuestro papel como historiadores en los debates sobre la producción y la representación pública del pasado.
} 
que el hecho de erguirse, de conquistar la posición vertical, simbólicamente "está dirigida a posibilitar la facultad de discernir a distancia por la vista" (p. 34). Verónica Zárate también señala cómo la altura de los monumentos y algunos de sus elementos accesorios (escalinatas, rampas, rejas) les brindan una inaccesibilidad física que refuerza su glorificación simbólica ${ }^{10}$.

Al costado de la Estela de Luz se encuentran unas escalinatas que originalmente estaban pensadas como foro y lugar de encuentro, y que dan acceso al sótano que se encuentra bajo el monumento, donde actualmente funciona el Centro de Cultura Digital (CCD). Este espacio, que depende de la Secretaría de Cultura, está dedicado a la investigación de las implicaciones culturales, sociales y económicas del uso cotidiano de la tecnología digital, concentrándose en el desarrollo de diversos programas, talleres, exhibiciones, conciertos, ciclos de cine, proyectos editoriales, etc. El CCD busca que sus actividades "sean puntuales, tomen en cuenta las necesidades específicas de cada comunidad [...] e impulsen la inclusión de grupos que sufran rezago en la adopción de nuevas tecnologías" (CCD, 2012).

La idea del Gobierno Federal de construir un monumento-arco conmemorativo para el Bicentenario de la Independencia se dio a conocer en una ceremonia oficial en el Castillo de Chapultepec el 26 de enero de 2009, en la cual se lanzó el concurso dirigido a un número restringido de arquitectos (treinta arquitectos y seis despachos). Los requisitos que debían observar los interesados en participar eran los siguientes:

El Anteproyecto debía ser diseñado como hito urbano-arquitectónico, contemporáneo, abstracto y de gran altura, símbolo de la unidad nacional y emblema del México moderno, como remate del trazo original del Paseo de la Reforma construido en 1865; habría de contar con un monumento (Arco) emblemático para conmemorar la gesta de la Independencia, una plaza o espacio público, un "stand" de turismo de $6.0 \mathrm{~m}^{2}$, un "stand" de ventas de documentos y objetos conmemorativos de $12.0 \mathrm{~m}^{2}$ y una bodega de $12.0 \mathrm{~m}^{2}$ (AUDITORÍA SUPERIOR DE LA FEDERACIÓN, 2013).

\footnotetext{
${ }^{10}$ Como en el caso de la columna de la Independencia, "que desde 1910 vigila el Paseo de la Reforma y cuya Victoria alada, hecha por Enrique Alciati, parece volar a más de 30 metros del pavimento, logrando así una separación tajante con el transeúnte" (2011, p. 424).
} 
Llama la atención que dentro de las condiciones fijadas por el gobierno se solicite la construcción de un monumento "contemporáneo" al mismo tiempo que se exige que revista una forma arquitectónica tradicional (el arco). También resulta interesante la mención al stand de turismo y al de ventas, que evidencian una intención del gobierno de consolidar el nuevo "lugar de memoria" como punto de interés dentro del circuito turístico y comercial del centro de la capital. El proyecto ganador fue "Estela de Luz", de César Pérez Becerril, que compitió contra otras 35 propuestas ${ }^{11}$. Por razones que explicaré más adelante, el proyecto original es muy distinto del monumento tal como se materializó: comprendía un parque, fuentes de agua, un centro de divulgación histórica y ocupaba una extensión cuatro veces más grande que la actual.

Según el arquitecto César Ramírez, este monumento guarda una estrecha relación simbólica con el pasado prehispánico: sus desniveles, la plaza y la Estela, representan los planos de la cosmología mexicana antigua (los 13 cielos, la tierra y los nueve niveles del inframundo); los 104 metros de altura representan dos veces cincuenta y dos, que en el mundo mesoamericano constituían un ciclo completo. El cuarzo, a su vez, es "incoloro, neutro, referente de respeto hacia cualquier color, forma de pensamiento o creencia" fue uno de los materiales más preciados del México Antiguo, “junto con las plumas de

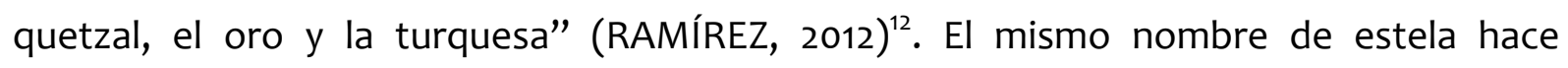
referencia a la tradición maya de erigir estelas para registrar acontecimientos históricos:

\footnotetext{
${ }^{11}$ No me fue posible indagar sobre las demás propuestas, ni sobre los criterios que condujeron al jurado a decretar la de Pérez Becerril como la ganadora. En todo caso, el hecho de que la propuesta seleccionada incumpliera uno de los requisitos establecidos (no es un arco) contribuyó a colocar un manto de sospecha sobre la historia del monumento desde el comienzo.

${ }^{12}$ Según su creador, la Estela representaba una gran ceiba que atraviesa los diferentes planos, desde sus raíces hasta su copa. En una entrevista, se queja de que los constructores no respetaron ese sentido y colocaron equivocadamente las placas de cuarzo: "se está colocando el cuarzo de manera arbitraria, mi equipo trabajó meses teniendo registro fotográfico de cada placa de cuarzo para elaborar un mapeo de las caras de la Estela que asemeja una gran ceiba que nace del centro de la tierra, cuyo tronco y ramas sostiene el cielo y cuyas raíces penetran en el inframundo: densidad de vetas en el centro y la base, depurándose conforme se eleva" (SÁNCHEZ, 2011).
} 
El proyecto tomó su inspiración conceptual de la tradición de los pueblos del México Antiguo, especialmente del pueblo maya cuyos gobernantes erigían estelas de piedra grabada para conmemorar eventos relevantes. De tal suerte el monumento fue concebido como dos esbeltas placas de ónix de 106 metros de altura, cada una representando cien años de independencia mexicana que en la noche habrían de iluminarse y que desde la distancia se verían como una columna de luz (CIUDAD DE MÉXICO, 2014).

Así mismo, las paredes del espacio conmemorativo y del sótano del mismo se proyectaron para ser recubiertas con otro material conocido y trabajado por las sociedades prehispánicas: la obsidiana. Según Pérez Becerril, la idea era que en los muros se inscribiera un mensaje conmemorativo en español y 62 "lenguas vivas" habladas en México, y que en el sótano funcionara un "espacio de difusión histórica en primer nivel” y un lugar de contemplación y reflexión que emulara un “oráculo de la época prehispánica” (PALMA, MIRANDA y ROSAS, 2015).

El monumento también está relacionado con la historia del México "moderno", pues las dos torres que dan forma a la Estela representan cada una un siglo marcado por una gesta patriótica: la Independencia (1810) y la Revolución (1910). En pocas palabras, el monumento representa los doscientos primeros años de México como Estado-nación moderno independiente. "En su discurso inaugural, el entonces presidente mencionó que era un homenaje a todos los héroes que habían formado parte de la historia de esta nación y la estructura está conformada por dos planchas de acero recubiertas de cuarzo porque cada una representa un siglo de historia" (AJA, 2016, pp. 30-31).

En suma, en cuanto al sentido histórico y las representaciones históricas que despliega el monumento, podemos concluir que el monumento retomó algunos elementos conceptuales y materiales de la cultura y de la historia de los pueblos prehispánicos (sin que esto implicara un reconocimiento a las comunidades indígenas contemporáneas, cuyas "lenguas vivas" jamás llegaron a incorporarse en la materialización del monumento), rinde homenaje a los dos grandes acontecimientos que moldearon la nación mexicana (Independencia y Revolución) y a sus héroes -en abstracto-, y expresa un mensaje de optimismo, esperanza y "luminosidad" de cara a un futuro incierto. 
Desde el principio, el proyecto de construcción de la Estela de Luz estuvo plagado de irregularidades, falta de coordinación entre las instituciones responsables y fuertes sospechas de corrupción. El monumento, cuya inauguración estaba prevista para el 16 de septiembre de 2010, tuvo un retraso de 15 meses (se estrenó en enero de 2012) y costó un 192\% más de lo presupuestado en un inicio (de 393 mdp, pasó a costar $1.304 \mathrm{mdp}$ ), y solo se construyeron $8,138 \mathrm{~m}^{2}$ de los $34,877 \mathrm{~m}^{2}$ previstos en el proyecto (EL ECONOMISTA, 2013).

En 2009, la obra se encargó a I.I.I. S.A. de C.V., una empresa de infraestructura filial de PEMEX (la petrolera estatal). Sin embargo, dicha empresa no contaba con la capacidad de realizar el monumento, por lo que subcontrató la obra en un 100\%, generando demoras, sobrecostos y procediendo irregularmente. Encargaron la obra (mediante proceso de invitación particular y no de licitación pública) a las empresas GUTSA (una empresa inhabilitada y sancionada en el pasado por incumplimiento, cuyos dueños están afiliados al PAN, partido de gobierno) y a Proyectos y Desarrollos de Infraestructura (SAPI), quienes a su vez subcontrataron otras 13 empresas. I.I.I. celebró con GUTSA-SAPI cuatro convenios modificatorios al contrato original, lo que derivó en la extensión de los plazos de entrega y costos del monumento, sin que esto fuera cuestionado por Banjército (banco encargado del fideicomiso del Bicentenario), el INEHRM o la SEP (encargados de la conmemoración). El proyecto original fue modificado y se impidió al arquitecto Pérez Becerril y su equipo intervenir en la obra, a la vez que sus advertencias y ajustes fueron ignorados (por ejemplo, el Instituto Politécnico Nacional realizó estudios de suelos a $35 \mathrm{~m}$ de profundidad que no sirvieron, pues era necesario que se realizaran a mayor profundidad). La Auditoría Superior de la Federación determinó que existieron pagos excesivos en la compra, transporte e instalación del acero. GUTSA utilizó un tipo de cuarzo distinto al que supuestamente compró a la compañía italiana Taltos, sin que Banjército o I.I.I. realizaran verificación alguna de la autenticidad de dicho material. Turissste gastó 15 millones de pesos para el magno evento de lanzamiento de convocatoria y 1.8 millones para la ceremonia de colocación de la primera piedra (AUDITORIA SUPERIOR DE LA FEDERACIÓN, 2013; AVILÉS, GARDUÑO y MENDEZ, 2013). Ante estas situaciones, la Auditoría Superior de la Federación llegó a la conclusión de que 
las múltiples instancias que participaron en el Comité Técnico del Fideicomiso, así como I.I.I. Servicios, S.A. de C.V. y el BANJÉRCITO, tomaron decisiones sin una adecuada coordinación y la plena observancia de la normativa para asegurar la eficacia, eficiencia y economía en el uso de los recursos públicos, lo que propició que el costo de la construcción se elevara en $192.0 \%$ respecto del contratado originalmente y que la inauguración se realizara el 7 de enero de 2012, más de 15 meses después de la fecha prevista originalmente (15 de septiembre de 2010)(2013, p. 13).

En consecuencia, el ente fiscalizador emitió 106 observaciones, que generaron 142 acciones: 36 recomendaciones, 5 solicitudes de aclaración, 1 promoción del ejercicio de la facultad de comprobación fiscal, 86 promociones de responsabilidad administrativa sancionatoria, 11 pliegos de observaciones y 2 denuncias de hechos. Adicionalmente, en el transcurso de las auditorías que este ente practicó a las instituciones involucradas, se presentaron 29 solicitudes de intervención de las instancias de control competentes. No obstante, hasta la fecha solamente se han procesado a ocho personas, sin que se haya concretado ninguna condena. Se trata de ocho ex funcionarios de la empresa I.I.I., a quienes se les giró orden de captura el 11 de abril de 2013 por uso indebido de aprehensiones y facultades. Su abogado, Gabriel Regino García aseguró que sus clientes no incurrieron en "acto ilícito alguno", y declaró que son "chivos expiatorios", víctimas de la presión social sobre las autoridades. Los inculpados enfrentan el proceso en libertad pues los delitos de los que se acusan no son considerados "graves", y porque en 2015 una juez federal les levantó la garantía de 1.035 millones de pesos que otro juez les había impuesto para poder permanecer en libertad. Llama la atención que no se encuentren bajo investigación personas vinculadas a GUTSA-SAPI ni a ninguna de las entidades gubernamentales implicadas en la construcción del monumento (BARAJAS, 2013; GONZÁLEZ, 2013; SÁNCHEZ, 2013).

La Estela de Luz se inauguró, finalmente, el 7 de enero de 2012. Para tal ocasión, se realizó una ceremonia oficial con cerca de quinientos invitados. Luego de dar un discurso inaugural, el presidente Calderón y la primera dama Margarita Zavala se acercaron a tocar una de las más de mil placas de cuarzo que conforman el monumento para darlo por inaugurado. Acto seguido, comenzó un conteo regresivo, “diez números recorrieron los 
104 metros de altura, en la cima el número uno y con ello la torre finalmente se iluminó". La palabra "México" se formó con letras luminosas en la Estela. También hubo un espectáculo musical: la orquesta sinfónica juvenil de Carlos Chávez interpretó el tema “Estela de Luz" compuesta por Luis Antonio Rojas, y las interpretaciones de la soprano Lourdes Ambriz y del DJ Alyosha Barreiro, junto con los juegos pirotécnicos, cerraron el evento (RAMíREZ, 2012). En su discurso, Calderón no mencionó ni felicitó al arquitecto responsable del diseño del monumento ni hizo referencia a las denuncias sobre irregularidades y corrupción, pero sí recordó que la Estela se había erigido en honor a los héroes que habían participado en la Independencia y la Revolución, y que era un símbolo de unidad y esperanza para los mexicanos: "la Estela de Luz está llamada a iluminar el siglo XXI mexicano. Y más allá de las naturales controversias que este tipo de obras suelen generar, será un icono de la ciudad capital” (CRUZ, 2010, s/p).

\section{Estela desplazada y reapropiada: corrupción, estudiantes, galletas y desaparecidos}

Sin embargo, la Estela dista mucho de haberse convertido en icono de la ciudad, reconocido y apreciado como símbolo colectivo por parte de la ciudadanía. El hecho de que los materiales empleados en la construcción sean extranjeros (acero finlandés, cuarzo brasileño y luces leds alemanas), el sobrecosto de $192 \%$ y la demora de 15 meses en su estreno “enturbiaron desde un inicio su popularidad entre los mexicanos, dando mayor peso a la problemática político-social que al proyecto y su función simbólica en sí" (AJA, 2016, p. 31). Al parecer, para la población no ha sido posible ir más allá de las "naturales controversias" a las que se refería Calderón, y el monumento al Bicentenario ha sido llamado "monumento a la corrupción”, "monumento a la ineptitud del Gobierno Federal”, "faro de las lamentaciones", "agravio de 104 metros", etc. (RESÉNDIZ, 2010; VILLORO, 2012) $)^{13}$. La sátira también ha sido empleada como táctica de expresión del

\footnotetext{
${ }^{13}$ En su columna, Villoro se refiere a la Estela como una "prueba en piedra de la corrupción, fastuoso derroche en una nación donde la Auditoría Superior de la Federación informa que 50 mil escuelas no tienen agua potable, la Estela es un agravio de 104 metros". Al respecto, el urbanista e historiador Héctor Quiroz plantea la siguiente reflexión: "la pobreza constituye una condición estructural que limita considerablemente el disfrute de los derechos esenciales de la ciudadanía. Si las condiciones materiales
} 
su parecido con una galleta comercial del mismo nombre (PALMA, MIRANDA y ROSAS, $2015)^{14}$.

Según varios expertos en urbanismo, "la falta de visión para el diseño de la ciudad, así como la nula identificación por parte de la ciudadanía con una de las grandes obras del Bicentenario, la ha llevado a que pase desapercibida y pierda su significado" (PALMA, MIRANDA y ROSAS, 2015, s/p). Este diagnóstico coincide con la opinión de los transeúntes entrevistados en las notas periodísticas citadas y con lo que pude corroborar a través de la observación etnográfica realizada para esta investigación: las personas que habitan, trabajan o transitan en el sector donde está emplazado el monumento, se apropian del espacio (usan las escalinatas como bancas y el lugar como un punto de encuentro y/o referencia), pero no del monumento como tal; muchos desconocen que allí funciona el CCD, y si lo conocen, ignoran cuáles son sus objetivos y su agenda cultural. La mayoría identifica la Estela de Luz no con la Independencia, el Bicentenario o los héroes nacionales, sino con la corrupción, la galleta suavicrema o la prepotencia del gobierno de Calderón de querer ser el "protagonista” de las conmemoraciones de 2010:

Fue un derroche de dinero. Se ve bonito de noche, pero no le veo la utilidad. La verdad es un desperdicio de luz ${ }^{15}$; en mi opinión la estela fue para que alguien se embolsara el dinero y punto [...] No tiene ninguna funcionalidad y solo es un símbolo fálico del gobierno anterior para decir "miren aquí puse mi torre", y con ello presumir que se hizo algo en el sexenio; es controversial, porque se gastó mucho dinero, y al final el monumento no tiene una funcionalidad más que prenderse en la noche y hasta ahí. Creo que debería aprovecharse el espacio para organizar festivales, así promoverlo ${ }^{16}$.

para una vida digna no están garantizadas, la libertad, la igualdad y la justicia tienen muy poca viabilidad social. Los monumentos y las conmemoraciones resultan entonces accesorios" (2012, p. 162).

${ }^{14} \mathrm{Al}$ buscar el término "suavicrema" en el motor de búsqueda Google aparece informaciones e imágenes sobre la Estela de Luz, y marginalmente sobre el producto de la marca Marinela.

${ }^{15}$ Testimonio de Miriam (PALMA, MIRANDA y ROSAS, 2015).

${ }^{16}$ Testimonios de Alexander, 30, arquitecto, y Humberto, 28, maestro (GARCíA, 2014). 
Adicionalmente, en varias ocasiones se han realizado protestas por los malos manejos y corrupción que rodearon la construcción del monumento, o los ciudadanos se han tomado la Estela como escenario para manifestaciones sobre otras problemáticas. La noche de inauguración, en la calle Lieja con avenida Chapultepec (lugar que ya se encontraba delimitado con bardas de seguridad para que solo tuvieran acceso a la ceremonia los invitados) se reunieron varios integrantes de algunos movimientos sociales -Movimiento Indignados, México Toma la Calle y Acampa Sur Coyoacán- para protestar por la corrupción detrás de la Estela. Los manifestantes aseguraron que no querían entrar al evento, alegando que no los invitaron, de la misma manera que no los consultaron sobre la inversión de más de mil millones de pesos "para construir una suavicrema”. Los manifestantes aseguraron "que en lugar de conmemorar la Independencia, la Estela de Luz debería ser el gran monumento a la corrupción” (CRUZ, 2012). El 15 de mayo de 2013, activistas de Greenpeace escalaron y colocaron una pancarta sobre la Estela de Luz para protestar en contra la siembra de maíz transgénico en México por parte de compañías transnacionales, con la connivencia del gobierno de Enrique Peña Nieto (SÁNCHEZ, 2013). El 24 de febrero de 2014, una persona encapuchada también escaló la Estela para desplegar en la cima una bandera de México y unas pancartas con los mensajes “Protestar no es un delito, revolución” y "Si querer una mejor educación, más seguridad, más trabajo, es delito, entonces somos delincuentes", lo cual movilizó a la policía y a cuerpos de rescate (SERVÍN, 2014).

Algunas de las manifestaciones más numerosas que se han registrado en la Estela de Luz fueron las convocadas por el movimiento social Yo soy $132^{17}$. Luego de haber realizado una marcha contra el "sesgo informativo" el 18 de mayo de 2012 (que contó con

\footnotetext{
17 Yo soy 132 fue un movimiento social conformado principalmente (pero no exclusivamente) por estudiantes de universidades privadas y públicas, que surgió en la coyuntura de las elecciones presidenciales de 2012 en México. El movimiento exigía la democratización de los medios de comunicación, un tercer debate entre candidatos presidenciales y el rechazo a la imposición mediática del candidato Enrique Peña Nieto. Precisamente, el movimiento surgió luego de que estudiantes de la Universidad Iberoamericana realizaron un boicot a la visita de ese candidato a la universidad, reclamándole por su responsabilidad en la represión de las protestas de San Salvador Atenco en 2006, en la cual se cometieron asesinatos, detenciones arbitrarias y violaciones sexuales, y tuvo lugar bajo su mandato como gobernador del Estado de México. El nombre del movimiento hace referencia a la identificación y apoyo al movimiento social como integrante número 132, luego de la publicación de un video en el que 131 estudiantes presentan algunos de los argumentos del movimiento.
} 
dos grandes recorridos: de la Universidad Iberoamericana a la sede de Televisa en Santa Fe; y del ITAM a la sede de Televisa en San Ángel), y una marcha nacional en contra de Enrique Peña Nieto al día siguiente, Yo soy 132 anunció un gran "mitin por la democratización de los medios" en el monumento Estela de Luz a realizarse el miércoles 23 de mayo. En la concentración, a la que acudieron miles de personas -en su mayoría estudiantes de la Universidad Iberoamericana, el IPN, el Tecnológico de Monterrey, la UNAM, etc.-, se dio a conocer un pliego petitorio de ocho puntos para la democratización de los medios de comunicación, en aras de un México más libre, próspero y justo (ANIMAL POLÍTICO, 2012a). Como acto de protesta, algunos manifestantes mancharon con pintura roja una de las caras de la Estela, pero "minutos después los propios jóvenes comenzaron a limpiar el monumento e instaron a respetar los inmuebles y edificios" (ANIMAL POLÍTICO, 2012b). Posteriormente, los contingentes marcharon hasta la Columna de la Independencia, y de allí algunos grupos se dirigieron al Zócalo, y otros a la sede de Televisa en Chapultepec.

Luego de un año de intensa actividad política y movilización social, Yo soy 132 volvió a convocar a una reunión en la Estela de Luz el 12 de mayo de 2013, esta vez para conmemorar su primer aniversario como movimiento. En un acto artístico y festivo, los estudiantes reiteraron los postulados que los habían llevado a converger hacía un año, e intervinieron, así fuera efímeramente, en el espacio monumental para contar su propia historia: elaboraron un mural que registraba la memoria colectiva del movimiento al pie de las escalinatas de la Estela de Luz, recordando con tizas de colores las fechas claves del mismo "desde su integración nacional como movimiento estudiantil, su participación en la contienda electoral, la realización de un debate ciudadano con los candidatos presidenciales y el cerco a Televisa" (POY SOLANO, 2013). En suma, resulta interesante cómo, a la vez que otros lugares físicos (como la Universidad Iberoamericana) o virtuales (las redes sociales), la Estela de Luz sea reconocida y apropiada por los mismos estudiantes como uno de los lugares donde se gestó, creció y obtuvo visibilidad pública el movimiento Yo soy 132.

Finalmente, uno de los intentos más importantes por apropiarse del monumento y resignificar su sentido original fue la iniciativa del Movimiento por la Paz con Justicia y 
Dignidad $^{18}$, encabezada por el poeta Javier Sicilia y apoyada por varios intelectuales y artistas reconocidos (académicos, cineastas, actores, poetas, novelistas, etc.). A finales del 2012, el movimiento hizo pública la propuesta de "transformación del monumento en Memorial de las Víctimas de la Violencia en México y Estela de Paz", presentando la solicitud formal al actual presidente Enrique Peña Nieto en enero de 2013 y publicando el exhorto en la Gaceta Parlamentaria de la Cámara de Diputados en abril del mismo año (AJA, 2016, p. 32).

Según Javier Sicilia, la Estela de la Paz debía convertirse en un faro para orientar al país "hacia una sociedad favorable al diálogo, la convivencia y la solidaridad, y la plaza pública que rodea el monumento está llamada a recordar a nuestros muertos, un espacio de reunión cultural y social abierto a las diferentes expresiones del arte y la cultura" (AJA, 2016, p. 36). El objetivo de convertir la Estela de Luz en un memorial para las víctimas de la violencia radicaría en documentar las vidas perdidas no solo en la lucha contra el narcotráfico del gobierno de Calderón, sino también “en la guerra sucia de los años setenta, los feminicidios en Ciudad Juárez, los caídos de Tlatelolco durante el movimiento estudiantil de 1968, así como los periodistas asesinados y desaparecidos" (DE LA ROSA, 2013). Para Sicilia, el monumento actual carece de sentido y legitimidad, "ya que se construyó en un sexenio de muerte, violencia e impunidad [...] fue edificada bajo la opacidad y la corrupción", motivo por el cual el movimiento convocó "a utilizar este monumento como un centro en donde la memoria no sea una entidad codificada o intocable, sino que se entienda como un proceso dinámico para entender el pasado y el futuro" (DE LA ROSA, 2013). La propuesta incluía la transformación del CCD en Centro de la Memoria y de la Paz, un lugar de documentación y divulgación con bases de datos e información sobre las víctimas de la violencia.

\footnotetext{
${ }^{18}$ Se trata de un movimiento social que se ha manifestado contra la violencia en las últimas décadas en México, expresada en crímenes tales como la desaparición forzada, los feminicidios, la trata de personas y la discriminación de los migrantes mexicanos en los Estados Unidos. El movimiento surgió tras el asesinato del líder y activista Juan Francisco Sicilia Ortega en Morelia (2011), acontecimiento que motivó la convocatoria a multitudinarias marchas a lo largo y ancho de México y de los Estados Unidos (Caravanas del Consuelo, del Perdón y de la Paz). Uno de los líderes visibles del movimiento es el poeta Javier Sicilia, padre de Juan Francisco (SICILIA y VÁZQUEZ MARTíN, 2016).
} 
La iniciativa del Movimiento por la Paz con Justicia y Dignidad fue apoyada en el Congreso por la diputada del Partido de la Revolución Democrática (PRD) e integrante de la Comisión de Derechos Humanos, Elena Tapia Fonllem, por otros legisladores de su partido, así como por el Partido del Trabajo y Movimiento Ciudadano (SÁNCHEZ, 2013). Sin embargo, no hubo una respuesta satisfactoria por parte del gobierno de Enrique Peña Nieto, la iniciativa nunca se concretó y la Estela de Luz no cambió de nombre ni de funciones.

Esto no impidió que el movimiento se apropiara del espacio monumental y lo transformara por medio de la introducción de uno de los soportes de memoria más conocidos: las placas conmemorativas. Durante el mes de marzo de 2014, y también en fechas más recientes, integrantes del movimiento instalaron varias placas sobre el suelo, en frente del monumento.

En la plazoleta de la intersección entre la puerta del Bosque de Chapultepec y la parte frontal de la Estela de Luz, se colocaron 42 placas en el piso llamadas Red de Eslabones de los Derechos Humanos, que rememoran algunas de las víctimas de la violencia en nuestro país, incluyendo nombres de civiles secuestrados y desaparecidos en diferentes Estados de la República, miembros del Ejército Mexicano, la Secretaría de la Marina y la Fuerza Aérea, miles de desaparecidos en el Estado de México, así como los 43 normalistas desaparecidos en Ayotzinapa (AJA, 2016, p. 37) $)^{19}$.

Algunas placas tienen nombres de personas específicas con una breve descripción de su edad, ubicación y situación en el momento de la desaparición. Casi todas presentan la fecha del 28 de marzo de 2014 (momento de su instalación), además de la fecha de su desaparición y/o muerte. Algunas se añadieron posteriormente, como las de los normalistas de Ayotzinapa. Una visita a este lugar revela que es un punto estratégico, pues es paso obligado de turistas, transeúntes y visitantes que caminan de Reforma al Bosque de Chapultepec (o viceversa). Es interesante comprobar cómo un porcentaje considerable de estas personas se detienen con curiosidad a leer el contenido de las placas, a observar la Estela de Luz, y es muy probable que se interroguen también por la

\footnotetext{
${ }^{19}$ Cabe aclarar que los 43 normalistas de la Escuela Normal Rural Raúl Isidro Burgos de Ayotzinapa fueron desaparecidos en Iguala (Guerrero), la noche del 26 de septiembre de 2014.
} 
relación entre ambas cosas -placas y estela-, entre ambos soportes de memoria, dos relatos distintos de la sociedad mexicana. Una nueva articulación de significado ha sido provocada, una capa más de sentido se ha añadido, una potencial reflexión en el ciudadano que interactúa con el monumento ha sido dispuesta. Todo esto sería imposible si el Movimiento por la Paz no hubiera instalado estas placas, que causan disonancia con el monumento Bicentenario original (Figura 2).

Figura 2: Placa instalada en las inmediaciones de la Estela de Luz.

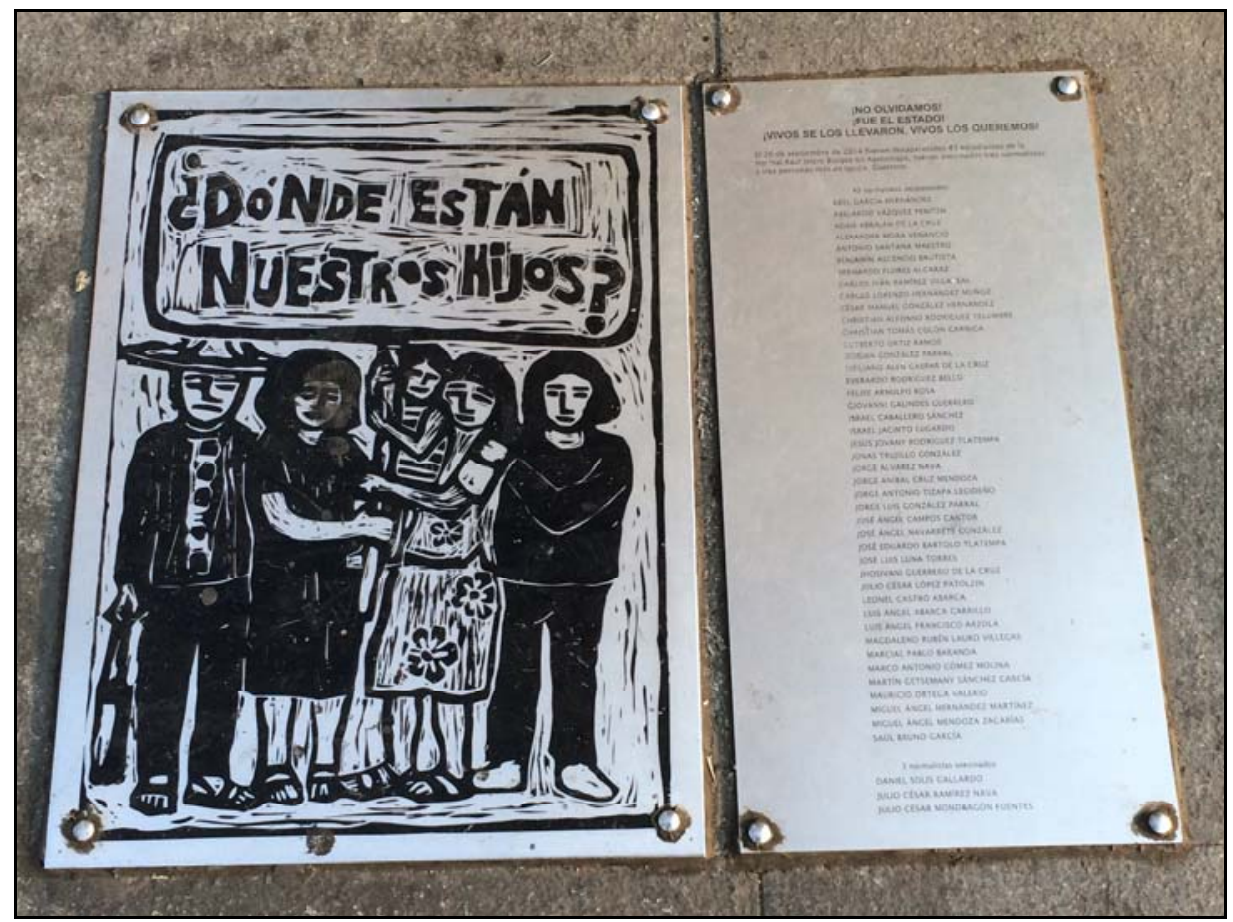

Fuente: Fotografía de Sebastián Vargas (2016).

\section{Conclusiones}

El monumento Estela de Luz es un artefacto cultural joven y "bastardo", en la medida en que nació ya contaminado. Según Aja, su significado es inestable y aún no termina de cuajar: ni la versión patriótica-oficial, ni su desplazamiento a partir de la sociedad civil que busca convertirlo en escenario de denuncia y movilización contra la violencia y la corrupción han logrado consolidarse. La "suavicrema" aparece, nuevamente, como el significado dominante de la Estela: 
La falta de promoción y el desconocimiento de la gente ante esta propuesta (la del Movimiento por la Paz), ha hecho que el nuevo sentido de la Estela de Luz tampoco se haya afianzado. Incluso se ha popularizado más el mote de "suavicrema" (galleta comercial de color y forma semejantes a la estela), que cualquiera de los otros sentidos: el originario o el de su transformación político-social (2016, p. 40).

Las vicisitudes de este reciente monumento constituyen un buen ejemplo para estudiar los usos públicos de la historia y su relación con proyectos políticos y sociales presentes, o, en otras palabras, para comprender mejor la influencia que la vida pública de la historia ejerce sobre el presente y la formación de nuestro futuro. Un "lugar de memoria" oficial que originalmente quiere conmemorar los dos grandes acontecimientos fundacionales de la nación moderna mexicana (doscientos años de Independencia y cien de Revolución) a la vez que hace referencia y homenajea a las culturas prehispánicas (pero sin lograrlo); un monumento que pierde su sentido conmemorativo original al ser banalizado y comparado con un producto de consumo cotidiano; una plaza pública para denunciar la corrupción y soberbia del gobierno saliente y la hegemonía antidemocrática del entrante; un contramonumento, finalmente, para recordar a las víctimas y narrar la historia de la nación a contrapelo, no en lo alto de la columna, sino en la humildad del suelo. Estas tensiones, diálogos y contradicciones que habitan y resignifican constantemente un mismo espacio, nos hablan del México contemporáneo, de cómo los mexicanos entienden su pasado, ven su presente y proyectan su futuro. $\mathrm{Y}$ es justamente en la tarea de historizar la multiplicidad de dimensiones que se entrelazan en un monumento o en la representación pública de la historia, que los historiadores podemos comenzar a participar, críticamente, de la "vida pública de la historia”. 


\section{Referencias}

ACHUGAR, Hugo. El lugar de la memoria, a propósito de monumentos (motivos y paréntesis). En: JELIN, Elizabeth y LANGLAND, Victoria. (Comps.). Monumentos, memoriales y marcas territoriales. Madrid: Siglo XXI, 2003, p. 191-216.

AJA, María del Pilar. La Estela de la Luz en el imaginario capitalino de la Ciudad de México. En: MUÑOZ, Carmen (Ed.). Pasados presentes. Debates por las memorias en el arte público en América Latina. Cali: Universidad del Valle, 2016, p. 29-43.

ALLIER, Eugenia y HESLES, José Carlos. Las vísperas de las fiestas del Bi/centenario en México. En: RODRíGUEZ, María Luisa (Ed.). Independencia y Revolución: contribuciones en torno a su conmemoración. México: UNAM, p. 367-400, 2010.

AUDITORÍA SUPERIOR DE LA FEDERACIÓN. Informe sobre la fiscalización superior del monumento Estela de Luz 2009-2011. 2013. Disponible en:

<http://www.asf.gob.mx/uploads/56_Informes_especiales_de_auditoria/Estela_Luz_Nv.p df $>$. Acceso en 15/08/2016.

CALDERÓN, Felipe. Discurso presidencial anuncio de la convocatoria para el anteproyecto del monumento emblemático arco del bicentenario. 2009. Disponible en: $<$ http://calderon.presidencia.gob.mx/2009/01/el-presidente-calderon-en-el-anuncio-de-laconvocatoria-para-el-anteproyecto-del-monumento-emblematico-arco-del-bicentenario/>. Acceso en 15/08/2016.

CALDERÓN, Felipe. México 2010. Crónica y memoria. México: Presidencia de la República/SEP/ CONACULTA/INEHRM, 2010.

CARRERAS, Juan José y FORCADELL, Carlos (Eds.) Usos públicos de la historia. Madrid: Marcial Pons/Prensas Universitarias de Zaragoza, 2003.

CARRILLO, Veremundo. Graffiteando la historia: la conmemoración del Bicentenario de independencia de México. Revista CCHS. Santiago de Chile: Corporación Chilena de Estudios Históricos. v.1, n.2, p. 22-54, junio de 2010.

CENTRO DE CULTURA DIGITAL. EI CCD. 2012. Disponible en: <<http://www.centroculturadigital.mx/es/el-ccd.html, 2012>. Acceso en 15/08/2016.

CHAKRABARTY, Dipesh. The public life of history: an argument out of India. Postcolonial Studies. North Melbourne: The Institute of Postcolonial Studies, v. 11, n.2, p. 169-190, 2008. 
CIUDAD DE MÉXICO. Estela de la Luz. 2014. Disponible en:

<http://www.ciudadmexico.com.mx/atractivos/estela_luz.htm>. Acceso en 15/08/2016.

DICKINSON, Greg; BLAIR, Carole y OTT, Brian (Eds.). Places of public memory. The rethoric of Museums and Memorials. Tuscaloosa: University of Alabama Press, 2010.

GARCIADIEGO, Javier. La política de la historia. Las conmemoraciones de 2010. En: PANI, Erika y RODRÍGUEZ KURI, Ariel (Coords.). Centenarios: conmemoraciones e historia oficial. México: El Colegio de México, 2012, p. 333-369.

GUEDEA, Virginia. Iniciativas gubernamentales, académicas y privadas para la conmemoración del Bicentenario en México. En: GUTMAN, Margarita Gutman y MOLINOS, Rita (Eds.). Construir bicentenarios latinoamericanos en la era de la globalización. Buenos Aires: Infinito, 2012, p. 125-146.

HABERMAS, Jürgen y LEAMAN, Jeremy. Concerning the public use of history. New German Critique, Ithaca: Cornell University, v. 14, n. 44, p. 40-50, spring/summer 1988.

HABERMAS, Jürgen; MANN, Thomas Mann y NOLT, Ernst. Hermano Hitler. El debate de los historiadores. México: Herder, 2012.

HOELSCHER, Steven y ALDERMAN, Derek. Memory and place: geographies of a critical relationship. Social \& Cultural Geography, London: Taylor \& Francis, v. 5, n. 3, p. 347-355, sept 2004.

JELIN, Elizabeth y LANGLAND, Victoria, (Comps.). Monumentos, memoriales y marcas territoriales. Madrid: Siglo XXI, 2003.

KOSELLECK, Reinhart. Modernidad, culto a la muerte y memoria nacional. Madrid: Centro de Estudios Políticos y Constitucionales, 2011.

LACAPRA, Dominick. Reflexiones sobre el debate de los historiadores. Representar el Holocausto. Historia, teoría, trauma. Buenos Aires: Prometeo, 2008.

MARTÍNEZ ASSAD, Carlos. La patria en el Paseo de la Reforma. México: Fondo de Cultura Económica, 2011.

NORA, Pierre. Pierre Nora en Les lieux de mémoire. Montevideo: Trilce, 2008. 
QUIROZ, Héctor. Proyectos urbanos y derechos ciudadanos en Ciudad de México. En: GUTMAN, Margarita y MOLINOS, Rita (Eds.). Construir bicentenarios latinoamericanos en la era de la globalización. Buenos Aires: Infinito, 2012, p. 147-164.

SAID, Edward. Invention, memory and place. En: MITCHELL, Timothy (Ed.). Landscape and power. Chicago: Chicago University Press, 2002, p. 241-259.

SICILIA, Javier y VÁZQUEZ MARTÍN, Eduardo (Eds.) El Movimiento por la Paz con Justicia y Dignidad. México: Ediciones Era, 2016.

SMITH, Anthony. Conmemorando a los muertos, inspirando a los vivos. Mapas, recuerdos y moralejas en la recreación de las identidades nacionales. Revista Mexicana de Sociología, México: UNAM, v. 60, n. 1, p. 61-80, ene/mar 1998.

REAL ACADEMIA ESPAÑOLA. Monumento. 2014. Disponible en: <http://dle.rae.es/?id=PIDhkfD, 2014>. Acceso en 15/08/2016.

RíOS, Carlos Alberto. Reflexiones sobre un acontecimiento: la conmemoración del bicentenario, la memoria y el presente. Anos 90, Porto Alegre: Universidad Federal do Río Grande do Sul, v. 22, n. 42, p. 193-205, diciembre de 2015.

SCHINDEL, Estela. Inscribir el pasado en el presente: memoria y espacio urbano. Política y Cultura, México: UAM-Xochimilco, n. 31, p. 65-87, primavera 2009.

TORRE, Susana. Ciudad, memoria y espacio público. El caso del monumento a los detenidos y desaparecidos. Memoria y Sociedad, Bogotá: Universidad Javeriana, v.10, n. 20, p. 17-24, ene/jun 2006.

TOVAR, Bernardo. Porque los muertos mandan. El imaginario patriótico de la historia colombiana. En: ORTIZ, Carlos y TOVAR, Bernardo (Eds.). Pensar el pasado. Bogotá: Universidad Nacional /Archivo General de la Nación, 1997, p. 125-169.

VENTEO, Daniel. Un ejemplo paradigmático de manipulación histórica del espacio público: la reforma del «Barrio Gótico» de Barcelona. En: FORCADELL, Carlos et. al. (Coord.). Usos públicos de la historia. IV Congreso de la Asociación de Historia Contemporánea. Zaragoza: Universidad de Zaragoza, 2002, p. 284-294.

YOUNG, James. The texture of memory: Holocaust memorials and meaning. New Haven: Yale University Press, 1993.

YOUNG, James. Memoria y contramemoria: hacia una estética social de los monumentos del Holocausto. En: ORTEGA, Francisco (Ed.). Trauma, cultura e historia: reflexiones interdisciplinarias para el nuevo milenio. Bogotá: Universidad Nacional, 2011, p. 375-409. 
ZÁRATE, Verónica. El papel de la escultura conmemorativa en el proceso de la construcción nacional y su reflejo en la ciudad de México en el siglo XIX. Historia Mexicana. México: El Colegio de México, v. 53, n. 2, p. 417-446, oct/dic 2003.

\section{Prensa}

ANIMAL POLÍTICO. "Yo soy 132": Declaratoria y pliego petitorio, México, mayo 23 de 2012. Disponible en: <http://www.animalpolitico.com/2012/05/declaratoria-y-pliegopetitorio-de-yo-soy-132/>. Acceso en 15/08/2016.

ANIMAL POLÍTICO. "Yo soy 132": Organizan asamblea el sábado en la Plaza de las Tres Culturas, México, 24 de mayo de 2012. Disponible en: <http://www.animalpolitico.com/2012/05/marcha-yo-soy-132-avanzara-hacia-el-angel-de-laindependencia/>. Acceso en 15/08/2016.

AVILÉS, Karina; GARDUÑO, Roberto y MÉNDEZ, Enrique. Estela de la luz la corrupción en cadena. La Jornada, México, 21 de febrero de 2013. Disponible en: <http://www.jornada.unam.mx/2013/02/21/politica/002n1pol>. Acceso en 15/08/2016.

BARAJAS, Abel. Da juez respiro a inculpados por Estela. Reforma, México, 28 de marzo de 2016. Disponible en: <http://www.reforma.com/aplicaciones/articulo/default.aspx?Id=803657>. Acceso en $15 / 08 / 2016$.

CRUZ, Ángeles. Inauguran Estela de la Luz, “Ícono de la ciudad capital”. La Jornada, México, 8 de enero de 2012. Disponible en: < http://www.jornada.unam.mx/2012/01/08/politica/o02n1pol>. Acceso en 15/08/2016.

DE LA ROSA, Yared. Que estela sea para recordar víctimas. Razón, México, 3 de abril de 2013. Disponible en: <http://www.razon.com.mx/spip.php?article166257>. Acceso en 15/08/2016.

GARCÍA, Víctor. La breve historia de la Estela de la Luz tras su inauguración. Crónica, México, 18 de agosto de 2014. Disponible en:

<http://www.cronica.com.mx/notas/2014/851534.html>. Acceso en 15/08/2016.

GONZÁLEZ, Isabel. Dictan formal prisión a 8 funcionarios por Estela de la Luz. Excélsior, México, 22 de mayo de 2013. Disponible en:

<http://www.excelsior.com.mx/nacional/2013/05/22/900383>. Acceso en 15/08/2016. 
EL ECONOMISTA. Costo de la estela de la luz se elevó 192\%. El Economista, México, 27 de marzo de 2013. Disponible en: <http://eleconomista.com.mx/sociedad/2013/03/27/costoestela-luz-se-elevo-192>. Acceso en 15/08/2016.

PALMA, Jazmín; MIRANDA, Perla y ROSAS, Ketzalli. Estela de Luz en Reforma, obra devorada por la urbe. El Universal, México, 16 de noviembre de 2015. Disponible en: <http://www.eluniversal.com.mx/articulo/metropoli/df/2015/11/16/estela-de-luz-enreforma-obra-devorada-por-la-urbe>. Acceso en 15/08/2016.

POY SOLANO, Laura. Reivindica \#YoSoy132 principios que le dieron origen hace un año. La Jornada, México, 12 de mayo de 2013. Disponible en:

<http://www.jornada.unam.mx/2013/05/12/politica/005n1pol>. Acceso en 15/08/2016.

RESÉNDIZ, Francisco. Monumento Bicentenario, a la ineptitud: AMLO. El Universal, México, 1 de septiembre de 2010, Disponible en:

<http://www.eluniversal.com.mx/notas/705829.html>. Acceso en 15/08/2016.

SÁNCHEZ, Luis Carlos. César Pérez Becerril: desconocen la Estela de la Luz. Excélsior, México, 5 de diciembre de 2011. Disponible en: < http://www.excelsior.com.mx/node/791486>. Acceso en 15/08/2016.

SÁNCHEZ, Luis Carlos. Niegan ilícitos por Estela de la Luz. Excélsior, México, 16 de mayo de 2013. Disponible en:

<http://www.excelsior.com.mx/comunidad/2013/05/16/899628\#view-1>. Acceso en $15 / 08 / 2016$.

SERVÍN, Mirna. Joven encapuchado escala la estela de la luz en señal de protesta. La Jornada, México, 24 de febrero de 2014. Disponible en:

<http://www.jornada.unam.mx/ultimas/2014/02/24/joven-encapuchado-escala-la-estela-deluz-218.html>. Acceso en 15/08/2016.

VILLORO, Juan. La esquela de la luz. Etcétera, México, 13 de enero de 2012. Disponible en: < Disponible en: <http://www.etcetera.com.mx/articulo/Esquela+de+luz/11028>. Acceso en $15 / 08 / 2016$. 
